\title{
Modifications of the free radial forearm flap (RFF) used in total penile reconstruction
}

\author{
Basim M Zaki, MD; Khalid M El-Sherbiny, MD; Abdel Rahman Abdel Aal, MD; \\ Hazem M Aly, MD
}

Department of Plastic Surgery, Ain Shams University, Cairo, Egypt.

\begin{abstract}
The penis is an important genitourinary organ and its reconstruction needs certain requirements in order to obtain a satisfactory outcome. This paper presents modifications in the technique of total penile reconstruction utilizing the free radial forearm flap (RFF) including the use of the remnant phallic skin and corpora, the use of the deep inferior epigastric artery as a donor artery to supply the flap after transfer and the use of the saphenous vein to augment flap venous drainage. These modifications shared in improving the outcome as regards a better operative time, avoiding exposure of large vessels, namely the femoral vessels, and providing sensory and erotic sensation to the flap.
\end{abstract}

\section{Introduction:}

The most evident feature in sex differentiation is the presence of a normal penis, whose deficiency not only causes physiological dysfunction but inflicts a mental and psychological trauma to the patient. There is no clear definition of severe penile inadequacy but it is considered as an insufficient penile length and function to obtain successful sexual intercourse. This implies that puberty has ended and that the patient must be sexually active. Congenital conditions resulting in inadequate penile development, medically indicated penile amputations, trauma and failed reconstructions of congenital anomalies are the main reasons for severe penile inadequacy. ${ }^{1}$

Ideally, phalloplasty should address the following requirements: (1) Achieves near normal shape and size; (2) Penile shaft must contain a urethra to allow voiding in a standing position ; (3) Allow implantation of a penile stiffener in order to allow for intercourse; (4) The phallus should be sensitive to both tactile and erotic sensation; (5) Have the least donor site morbidity possible; and (6) To be performed in a single stage if possible. ${ }^{1}$ To satisfy the above-mentioned requirements, increasing efforts have been made to achieve an improvement in total phalloplasty techniques.

Different techniques have been described; nonsensate local tube pedicled flap using a random pattern midline abdominal flap, ${ }^{2}$ pedicled radial forearm flap, myocutaneous flaps as the gracilis muscle flap, ${ }^{3}$ axial pattern groin flaps; superficial circumflex iliac artery, superficial inferior epigastric artery and rectus abdominis muscle flap ${ }^{4}$ and free flaps with a defined neuro-vascular bundle as the radial forearm fasciocutanous flap, ${ }^{5}$ lateral arm flap ${ }^{6}$ and the ulnar forearm flap. ${ }^{7}$ All such techniques have enabled phallic reconstruction to evolve to its present state of art. Despite advances in surgical techniques there is no single ideal technique and each approach has its own drawbacks.

One-stage penile reconstruction using a free radial forearm flap transferred by microsurgical technique was first reported in China in 1984. ${ }^{5,8}$ Since then, methods of penile reconstruction using a composite tissue graft harvested from various sites such as the dorsum of the foot, $, 9,10$ the deltoid area of the upper arm, ${ }^{9,11}$ the lateral aspect of the arm $6,12-14$ and the lower extremity ${ }^{15}$ have been reported. Among these choices, the radial forearm flap has remained 
the most popular for phallic reconstruction. The flap is easily harvestable and the vascular pattern is constant. Furthermore, a segment of radial bone can be incorporated to form a compound osteocutaneous flap. The radial forearm flap still has some limitations; its circumference may not be able to accommodate the prosthesis, presence of hair in the urethra, the long time for return of sensation, and utilizing the femoral vessel as a donor for arterial supply which carries a high risk of complications.

The current study presents modifications of the technique in phallus reconstruction by anastomosing the vessels of the radial forearm flap (RFF) to the deep inferior epigastric vessels and saphenous vein in addition to incorporating the remnant phallic skin and corpora within the radial forearm flap.

\section{Patients and methods:}

The present study was conducted during a period of two years (May 2006-May 2008) on nine patients; ages ranged from 18-30 years, who underwent total penile reconstruction using microvascular transfer of the radial forearm flap. The procedure was done after thorough psychological assessment and patient consenting.

Patients with different indications for phalloplasty were included in the study; microphallus, crippled and shortened penis after hypospadius repair, epispadius and post traumatic penile loss Table(1). Sensation was tested preoperatively at the penile stump one week postoperatively, then after thirty days, 60 days and then monthly from there on for periods up to a year (mean 8 months) at both the phallic remnant and the neophallus. Superficial and erotic sensations were assessed; superficial sensation was assessed by cotton swabs and the progress of improvement of sensation was measured from the junction of the neophallus and phallic remnant towards the tip Table(2).

\section{Technique:}

Allen's test was done preliminarily on both forearms to ensure adequate blood flow through the ulnar artery after severing the radial vessels.
Flap marking was then done Figure(1). Urethral catheterization was performed in all cases, except in one patient where a suprapubic catheter was used Figure(2). After anesthetization of the patient, the recipient site was prepared by exposure and dissection of the vessels (deep inferior epigastric vessels and saphenous vein), the dorsal nerve of the penis and dissection of the skin and corpora of the microphallus or penile stump by one team. Another surgical team elevated the flap based on the radial artery with its vena comitantes and cephalic vein. The neophallus was created on-site; de-epithelialization of skin over the flap for urethral reconstruction, tubing was then done over a Foley's catheter (no. 12F$14 \mathrm{~F}$ ) followed by dissection of the flap from distal to proximal after identifying the radial vessels and the cephalic vein. Identification and dissection of the lateral cutaneous nerve was performed after dividing the neurovascular pedicle. The severed flap is transferred to the pubic region, and after performing the urethral anastomoses, the radial artery was anastomosed to the deep inferior epigastric artery. The venous anastomosis was performed between the radial artery vena comitantes and the deep inferior epigastric vein in addition to the cephalic vein to the saphenous vein for augmentation of venous drainage. Neural anastomosis (lateral cutaneous nerve of the forearm to the dorsal nerve of the penis) was then done. The skin of the microphallus was incorporated as a part of the ventral aspect of the neophallus aiming to offer better sensation.

Post operatively, patients were maintained on a prophylactic dose of low molecular weight heparin and low dose aspirin, broad spectrum antibiotics in addition to good hydration both parenterally and orally in the early few days. Flap monitoring was done via color and temperature assessment while maintaining the neophallus in a $45^{\circ}$ position. The patients remain in bed for a week postoperatively and the urinary catheter is removed after two weeks and voiding of the patient is checked.

Only one of the operated upon nine patients underwent insertion of a single rod malleable prosthesis a year postoperatively based on his request. 


\section{Results:}

The reconstructed penile shaft was $14-18$ $\mathrm{cm}$ long and $11-15 \mathrm{~cm}$ in circumference. Total flap survival was noticed in all patients, and there were no complications concerning the donor area. The donor site healed satisfactorily in all patients with $90-100 \%$ graft take. Some patients noted reappearance of sensation as early as a week postoperatively in the remnant phallic skin (minimal tactile and erotic sensation). Gaining of sensation in the neophallus appeared throughout the follow up period and was recorded. The mean range of follow-up was 8 months.

Of the nine operated upon patients, six developed urethral complications. Three patients developed a single urethrocutaneous fistula $(33.3 \%)$; two of them were at the junction between the neophallus and remnant phallic skin following suture disruption, and the third one was at the middle of the flap. All three patients were managed conservatively in the form of repeated dilatation and dressings. Three other patients developed multiple fistulae (33.3\%), one of these patients on follow up ended with a single urethral fistula. The two others are still on follow up and are prepared for exploration, excision of fistulae and urethral repair. Minimal disruption at the junction of the neophallus and remnant phallic skin without fistula formation occurred in one case which healed spontaneously with dressings.

Superficial sensation assessment using the cotton swab was found present yet diminished in the remnant phallic skin from the first week of examination gradually increasing to the preoperative state within a month. Sensation started to appear at the base of the neophallus within two months, gradually increasing towards the glans throughout the follow up period Table(2) except in one patient (case 5) who underwent exploration of the anastomosed sensory nerves at the base of the neophallus four months postoperatively. Gradual but slowly progressing superficial sensation appeared on follow up within the following 3 months.

Erotic sensation was present as noted by the patients in the remnant phallus. The shape and form of the reconstructed penis was satisfactory to all patients. Some of the operated upon patients are shown in Figures(2-4).

Table (1): Patients criteria.

\begin{tabular}{|c|c|c|c|c|}
\hline Case & Age & Diagnosis & Previous procedure & Complications \\
\hline 1 & 25 years & $\begin{array}{c}\text { Crippled short } \\
\text { penile stump }\end{array}$ & $\begin{array}{c}\text { Several operations for } \\
\text { repair of hypospadius }\end{array}$ & $\begin{array}{c}\text { Urethrocutaneous } \\
\text { fistula }\end{array}$ \\
\hline 2 & 17 years & $\begin{array}{c}\text { Crippled short } \\
\text { penile stump }\end{array}$ & Repair of hypospadius & Suture line disruptuion \\
\hline 4 & 24 years & $\begin{array}{c}\text { Epispadius with } \\
\text { short penis }\end{array}$ & Epispadius repair & $\begin{array}{c}\text { Urethrocutaneous } \\
\text { fistula }\end{array}$ \\
\hline 5 & 20 years & Microphallus & $\begin{array}{c}\text { No previous } \\
\text { operations done } \\
\text { undescended testis, }\end{array}$ & $\begin{array}{c}\text { Multiple fistulae } \\
\text { bladder surgery }\end{array}$ \\
\hline 6 & 30 years & $\begin{array}{c}\text { Post traumatic } \\
\text { deformed penis }\end{array}$ & Debridement & $\begin{array}{c}\text { Urethrocutaneous } \\
\text { fistula }\end{array}$ \\
\hline 7 & 27 years & Epispadius & Epispadius repair & $\begin{array}{c}\text { Multiple fistulae and } \\
\text { suture line disruption }\end{array}$ \\
\hline 9 & 21 years & Microphallus & $\begin{array}{c}\text { No previous } \\
\text { operations done }\end{array}$ & No previous \\
\hline
\end{tabular}


Table (2): Superficial sensation in the remnant phallic skin and neophallus throughout the follow up period (measurements from the base of the neophallus).

\begin{tabular}{|l|c|c|c|c|c|c|c|c|c|c|}
\hline & \multicolumn{2}{|c|}{ After 7 days } & \multicolumn{2}{c|}{30 days } & \multicolumn{2}{c|}{60 days } & \multicolumn{2}{c|}{120 days } & \multicolumn{2}{c|}{240 days } \\
\hline & Ph. Skin* & RFF & Ph. Skin & RFF & Ph. Skin & RFF & Ph. Skin & RFF & Ph. Skin & RFF \\
\hline 1 & diminished & - & + & - & + & $2 \mathrm{~cm}$ & + & $5 \mathrm{~cm}$ & + & $10 \mathrm{~cm}$ \\
\hline 2 & diminished & - & + & - & + & $2 \mathrm{~cm}$ & + & $5 \mathrm{~cm}$ & + & $8 \mathrm{~cm}$ \\
\hline 3 & diminished & - & + & - & + & $1 \mathrm{~cm}$ & + & $3 \mathrm{~cm}$ & + & $6 \mathrm{~cm}$ \\
\hline 4 & diminished & - & + & - & + & $0.5 \mathrm{~cm}$ & + & $3 \mathrm{~cm}$ & + & $5 \mathrm{~cm}$ \\
\hline 5 & diminished & - & + & - & + & - & + & $\mathrm{none}$ & + & $2 \mathrm{~cm}$ \\
\hline 6 & diminished & - & + & - & + & $1 \mathrm{~cm}$ & + & $4 \mathrm{~cm}$ & + & $7 \mathrm{~cm}$ \\
\hline 7 & diminished & - & + & - & + & $2 \mathrm{~cm}$ & + & $4 \mathrm{~cm}$ & + & $6 \mathrm{~cm}$ \\
\hline 8 & diminished & - & + & - & + & $1 \mathrm{~cm}$ & + & $3 \mathrm{~cm}$ & + & $6 \mathrm{~cm}$ \\
\hline 9 & diminished & - & + & - & + & - & + & $1 \mathrm{~cm}$ & + & $3 \mathrm{~cm}$ \\
\hline
\end{tabular}

* Remnant phallic skin, ** Radial forearm flap (neophallus).

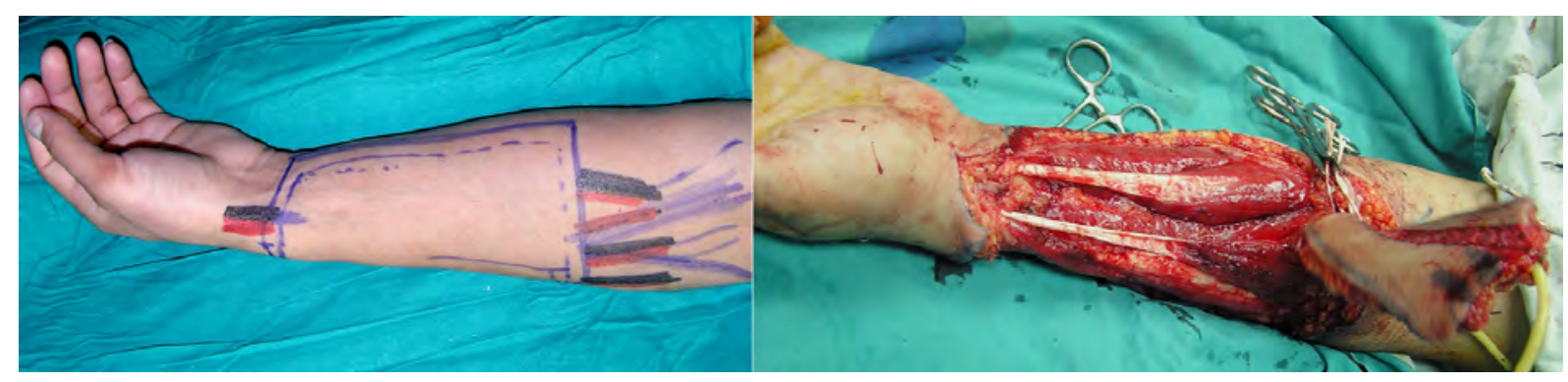

A) Flap design and elevation.

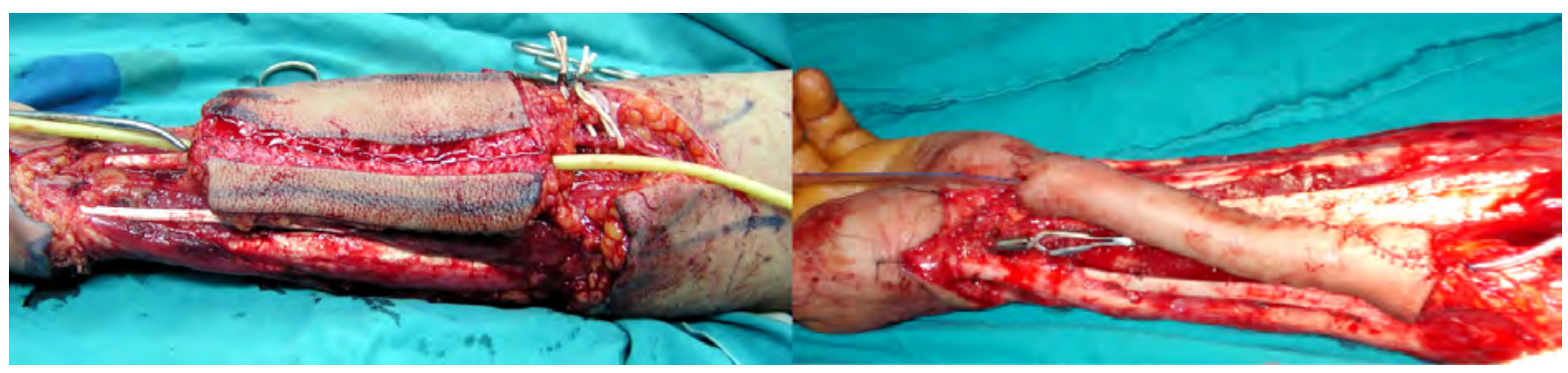

B) Tubing and urethral creation.

Figure (1): RFF elevation. 

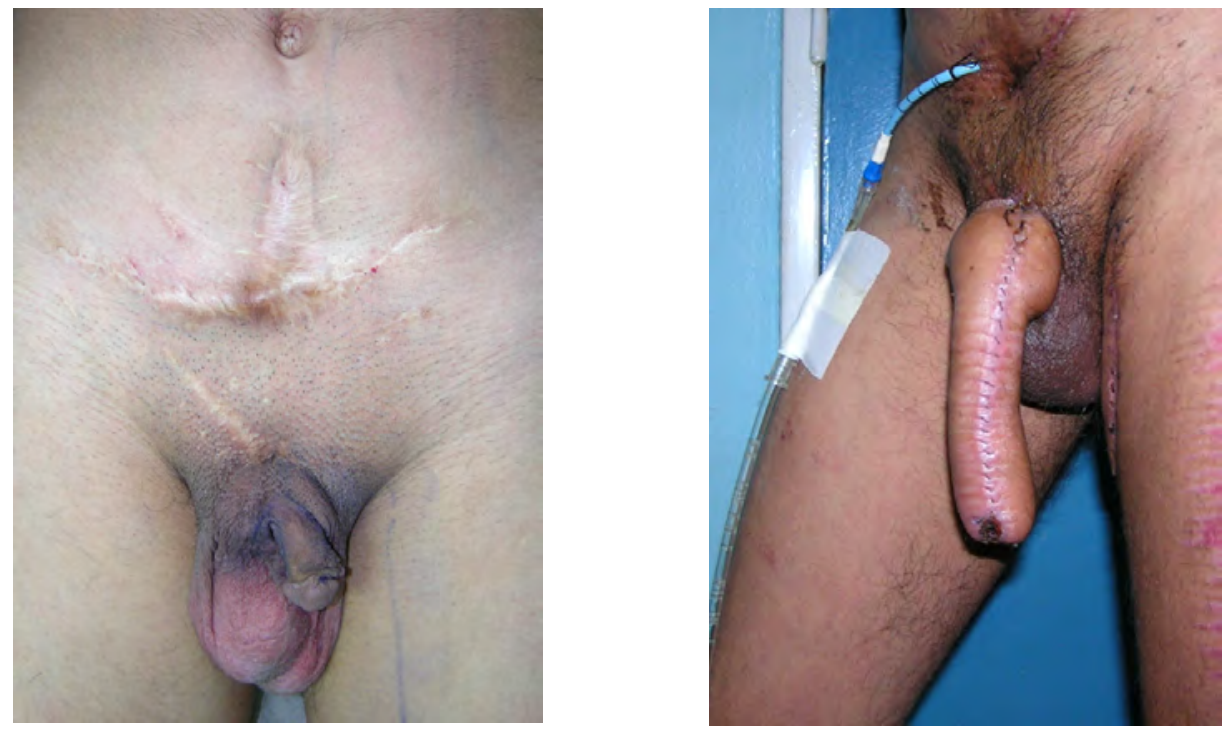

Figure (2): Case 4 (preoperatively and 2 weeks postoperatively).
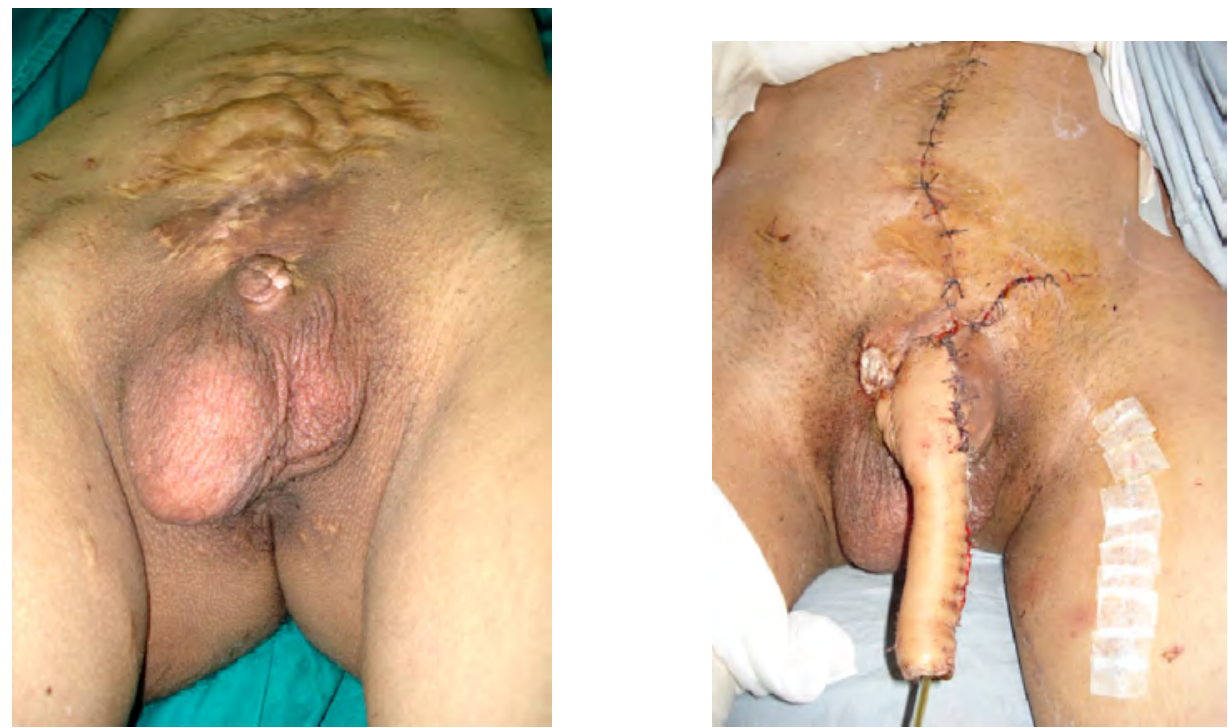

Figure (3): Case 7 (preoperatively and 2 weeks postoperatively).
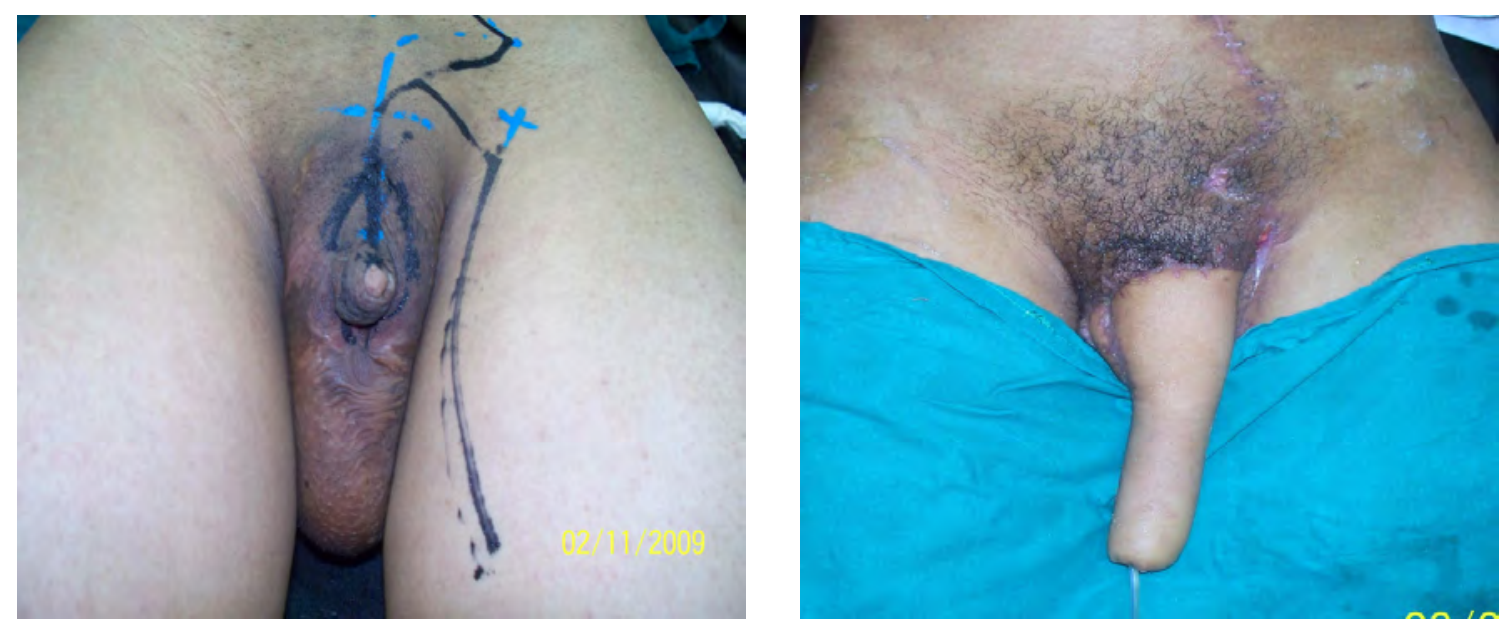

Figure (4): Case 8 (preoperatively and 2 weeks postoperatively). 


\section{Discussion:}

Reconstructive surgery for severe penile insufficiency is necessary due to the devastating effect on the psychological and sexual function. The goal of penile reconstruction is to achieve an aesthetically and functionally acceptable neophallus. The phallus should be constructed to an adequate size and bulk (possibly in a single stage), have enough rigidity to allow intromission, provide enough protective and erogenous sensation to allow enjoyment of intercourse; and should permit the urethra to exit at the glans tip without presence of strictures or fistulae.

Penile reconstructive surgery is a highly controversial issue due to the variable surgical techniques, variable results and non uniform evaluation method. The reconstructive procedure is indicated in various conditions as trauma and burns, circumcision accidents, ablative cancer surgery, gender reassignment and congenital anomalies. The development of microsurgical free-flap techniques made the first microsurgical phalloplasty possible using the free radial forearm flap. ${ }^{5}$ The radial forearm flap has been generally accepted as the best donor site for phalloplasty and is considered the golden standard in phalloplasty for femaleto-male transsexuals. ${ }^{16}$ This same technique can also be applied for severe penile insufficiency.

Rashid and Sarwar ${ }^{17}$ performed penile reconstruction in 36 patients using the radial forearm flap and documented one flap loss. In our current series, no complications concerning flap survival or donor site morbidity were reported with an acceptable aesthetic appearance. In this series, the RFF was the method used and the anastomosis was done with the deep inferior epigastric artery and one of its vena comitantes in addition to augmentation of venous drainage by anastomosis with the saphenous vein decreasing the incidence of complications due to venous congestion.

Hage and de Graaf ${ }^{18}$ in their series of intersex surgery positioned the clitoris directly below the phallic shaft. Gilbert et al. ${ }^{9}$ placed the clitorial remnant below the scrotum and inner thigh in all their cases as easier stimulation can be achieved during intromission.
In the current series, there were no patients demanding gender reassignment procedures and so the remnant penile skin and the redumentry or mutilated penis were incorporated within the under surface of the neophallus. With the presented technique, the reconstructed genitalia obtain an adequate tactile and erogenous sensibility earlier and better than the standard technique of RFF in phalloplasty. Presumably, the cooptation of the lateral cutaneous nerve of the flap with one of the 2 nerves of the microphallus is essential for obtaining long term erogenous sensation. Additionally, preservation of the skin and rudimentary corpora of the microphallus in the presented technique has helped in development of erotic sensation early following phalloplasty before appearance of superficial sensation.

Fang et al. ${ }^{19}$ phalloplasty series reported the rate of urethrocutaneous fistula was 38/56 $(67.8 \%)$ and Perovic ${ }^{20}$ recorded the best rate which was $2 / 24(8.3 \%)$. In the current series, the incidence rate $6 / 9(67 \%)$, which indicates that the urethral reconstruction is still as challenging as in other studies.

On the other hand, there are some limitations in the use of RFF such as the urethral hair growth, fistula and extrusion of the prosthesis. In the single patient who requested insertion of prosthesis, the circumference of the reconstructed penis was adequate for insertion of a single rod; this patient is not married yet so the evaluation of penetration power is yet to be determined.

The technique utilized in our study showed that the use of the deep inferior epigastric vessels and augmenting the venous drainage by anastomosing the cephalic vein to the saphenous vein showed no vascular or flap complications, obscures the need to expose and use the femoral vessels for anastomoses, and gives the patients early satisfaction because of sensate phallic remnant skin. This technique has shown to be easier and safer than using the larger femoral vessels, yet provided adequate blood flow in and out of the flap.

\section{Conclusion:}

The RFF flap allows the creation of a neophallus of good size and girth and good aesthetic appearance with better and early 
function and sensation. The presented modification allows for urethroplasty and safe implantation of a penile prosthesis. Urinary complications and problems with penile stiffeners are frequent and patients must be informed about the possible complications. Despite this, radial forearm phalloplasty is a valuable treatment option for severe penile insufficiency.

\section{References:}

1- Lumen N, Monstrey S, Ceulemans P, van Laecke E, Hoebeke P: Reconstructive surgery for severe penile inadequacy: Phalloplasty with a free radial forearm flap or a pedicled anterolateral thigh flap: Clinical study. Advances in Urology 2008; 1-5.

2- Gillies H, Millard DR: The principles and art of plastic surgery. Boston: Little, Brown (Publishers); 1957.

3- Orticochea M: A new method of total reconstruction of the penis. Br J Plast Surg 1972; 25: 347.

4- Puckett CL, Montie JE: Construction of male genitalia in the transsexual, using a tubed groin flap for the penis and a hydraulic inflation device. Plast Reconstr Surg 1978; 61: 523.

5- Chang TS, Hwang WY: Forearm flap in one-stage reconstruction of the penis. Plast Reconstr Surg 1984; 74: 251.

6- Upton J, Mutimer KL, Loughlin K, et al: Penile reconstruction using the lateral arm flap. J R Coll Surg Edinb 1987; 32: 97.

7- Gilbert DA, Schlossberg SM, Jordan GH: Ulnar forearm phallic construction and penile reconstruction. Microsurgery 1995; 16: 314.

8- Kao XS, Kao JH, Ho CL, et al: One-stage reconstruction of the penis with free skin flap: Report of three cases. J Reconstr Microsurg 1984; 1: 149.

9- Gilbert DA, Horton CE, Terzis JK, et al: New concepts in phallic reconstruction. Ann Plast Surg 1987; 18: 128.
10-Chen YB, Chen HC: Penile reconstruction for a victim of electrical injury with bilateral below-elbow amputations. Plast Reconstr Surg 1991; 87: 771.

11-Harashina T, Inoue T, Tanaka I, et al: Reconstruction of penis with free deltoid flap. Br J Plast Surg 1990; 43: 217.

12-Hage JJ, de Graaf FH, van den Hoek J, et al: Phallic construction in female-to-male transsexuals using a lateral upper arm sensate free flap and a bladder mucosa graft. Ann Plast Surg 1993; 31: 275. 13-Young VL, Khouri RK, Lee GW, Nemecek JA: Advances in total phalloplasty and urethroplasty with microvascular free flaps. Clin Plast Surg 1992; 19: 927.

14-Shenaq SM, Dinh TA: Total penile and urethral reconstruction with an expanded sensate lateral arm flap: Case report. $J$ Reconstr Microsurg 1989; 5: 245.

15-Sadove RC, Sengezer MMcRoberts JW, et al: One-stage total penile reconstruction with a free sensate osteocutaneous fibula flap. Plast Reconstr Surg 1993; 92: 1314.

16-Monstrey S, Hoebeke P, Dhont M, et al: "Radial forearm phalloplasty: A review of 81 cases," European Journal of Plastic Surgery 2005; 28(3): 206-212.

17-Rashid M, Sarwar SU: Avulsion injuries of the male external genitalia: Classification and reconstruction with the customized radial forearm free flap. Br J Plast Surg 2005; 58(5): 585-592.

18-Hage JJ, de Graaf FH: Addressing the ideal requirements by free flap phalloplasty: some reflections on the refinements of technique. Microsurgery 1993; 14: 592598.

19-Fang RH, Lin JT, Ma S: Phalloplasty for female transsexuals with sensate free radial forearm flap. Microsurgery 1994; 15(12): 895.

20-Perovic S: Phalloplasty in children and adolescents using extended pedicle island groin flap. J Urology 1995; 154: 848-853. 